\title{
Disorder of Endothelia Vessels' Functional State with Malignant Tumors in Patients Exposed Anthropogenic Radiation
}

\author{
Laura Pak $^{1 *}$, Yoshihiro Noso ${ }^{2}$, Nailya Chaizhunusova ${ }^{1}$, Zukhra Manambaeva ${ }^{1}$, \\ Tasbolat Adylkhanov', Nobuo Takeichi², Sayakhat Olzhaev ${ }^{3}$, Daniyar \\ Aldyngurov $^{4}$, Raikhan Tuleutayeva ${ }^{1}$, Ainur Argynbekova ${ }^{1}$, Gulyash Tanysheva $^{1}$, \\ Lashyn Zhazykbayeva ${ }^{1}$, Ainur Baissalbayeva ${ }^{1}$, Tolebay Rakhypbekov ${ }^{1}$
}

\begin{abstract}
The aim of this research is to determine the characteristics of endothelial factors and the hemostatic system conditions with malignant neoplasms patients, which were exposed to ionizing radiation. Total number of examined people is 223,153 of them are patients with gastrointestinal tract oncopathology. The article presents the results of the analysis of numerical indicators of endothelial condition and platelet hemostasis of patients, who had cancer. They lived in the regions of Kazakhstan, subjected to contamination of radionuclides as a result of nuclear weapons tests, which took place in this region from 1949 to 1989. These results then were compared to cancer patients and healthy individuals with no radiation risk. The study revealed the presence of higher levels of endothelial dysfunction and following trigger of the hemostatic system in patients with malignant tumors of the gastrointestinal tract. In particular, the defined high degree of endothelial dysfunction include endotheliumdependent vasodilation, content desquamated endothelial cells in peripheral blood and von Willebrand factor. These indicators have a clear correlation with the degree of disorder of studied parameters of the hemostasis, which can cause the development of thrombotic complications.
\end{abstract}

Keywords: Radiation - cancer - endothelium

Asian Pac J Cancer Prev, 17 (2), 575-579

\section{Introduction}

According to the literature it is known that the development of malignant tumors is the result of exposure to ionizing radiation during diagnostic procedures, the nuclear bombings, accidents and catastrophes, and as a result of nuclear tests (Bauer et al, 2005; Shore, 2009). It is very significant impact on the health of the population, according to the known research activity has Semipalatinsk nuclear test site (SNTS).

However, the opinion about the possibility of chronic radiation exposure influence (in low doses) led to the development of malignant neoplasm. And not all researchers concur with this opinion. There are theories of the threshold dose, of the nonlinear interaction of "doseeffect", and the nonthreshold linear theory (Moysich et al, 2002).

Nowadays, linear nonthreshold theory (Strzelczyk, 2007) received essential confirmation due to the results of conducted researches for revealing the connection between diagnostic methods using ionizing radiation and the risk of development of malignant neoplasms (Shah et al, 2012; Daly et al, 2015).
Main studies in the region of the Semipalatinsk nuclear test site were also carried out on the basis of the linear nonthreshold theory. The received results are sufficiently consistent with it. At the same time, it is impossible to associate many features of cancer morbidity in different regions of the Earth with the state of the natural radiation background. This item is a critically important argument for the threshold theory (Moysich et al, 2002; Laurier and Gay, 2015).

When considering the question about the effect of ionizing radiation on the development of neoplasm the key moment is its mutagenic effect. However, there are different directions of analysis, including mainly the condition of immune system. This option is considered as a key in the paper mentioned above (Shah, 2012). The concept of genesis of radiation-induced malignant neoplasms can have another aspect - the negative influence of radiation, including chronic low doses, on the morphology and function of the vascular endothelium. The condition of vascular endothelium is considered as a potential modifying factor in the genesis of oncological complications in radiation exposed individuals throughout all their lives (as the result of Semipalatinsk nuclear test site activity). 


\section{Materials and Methods}

Materials

Two groups of patients with stomach cancer, pancreatic and rectal cancer were formed. The total number of examined patients was 153 . The main group No.1 consists of 83 patients; the group No.2 consists of 70 patients. Also control group consists of 70 apparently healthy individuals (Table 1).

The age of patients was from 45 to 65 years old. The average age in the group was $59.7 \pm 2.0$ years.

The criteria for inclusion of patients in the main group were age, presence of verified diagnosis of malignant neoplasms on the basis of morphological examination, the poverty of specific anti-tumor therapy at the time of initial examination, the absence of any diagnostic procedures associated with exposure to ionizing radiation during the last 6 months, the presence of informed consent to his participation in the research and anonymous use of received data in scientific publications.

This study was approved by the meeting of the Ethics Committee of the Semey State Medical University from 11.13.2013, Protocol №2.

For the main group №1 additional inclusion criterion was established the presence of the calculation of the cumulative absorbed dose of 50 rem or higher as a result of living in emergency zones and the maximum radiation risk SNTS during the dose forming nuclear tests, ie irradiation in the mid and high doses.

Patients of the main group №2 lived in the regions of radiological safety lifelong (Almaty city).

The exclusion criteria are the presence of severe somatic co-morbidities (arterial hypertension II and up, ischemic heart disease, bronchial asthma, chronic obstructive pulmonary disease, chronic kidney diseases with renal insufficiency, cardiac insufficiency of any origin above the I functional class; chronic infectious diseases (tuberculosis, brucellosis, etc.); acute infectious diseases; conditions accompanied by a fever at the time of the initial examination; refusal to participate in the research at any stage.

Examination was performed after verificating the clinical diagnosis, before the specific antitumor treatment, such as chemotherapy, radiation therapy and before surgical intervention.

The control group consisted of 70 apparently healthy individuals. The average age of the group was 57.6 \pm 1.4 years. Control group individuals lived in the regions of radiological safety lifelong and did not have a history of episodes of radiotherapy.

\section{Methods of indicators of vascular-platelet hemostasis \\ The determination of platelet aggregation by Barkagan ZS (defined parameters: the index of spontaneous platelet aggregation (ISA), the total index of aggregation (TIA) and the index of spontaneous disaggregation (ISD)); the determination of quantity of von Willebrand factor (WF) in blood.}

\section{Methods for investigation of endothelial function}

The amount of exfoliated (circulating) endotheliocytes in the peripheral blood (CE) (Hladovec, 1978); metabolites NO (met. NO) amount in blood (Molina et al, 1995); determination of endothelium-dependent vasodilation (EDVD) (Celermajer, 1998).

\section{Statistical analysis}

The determination of the statistical significance of differences of indicators in the groups and the reliability of the correlations between indicators of the hemostatic system and endothelial function was carried out by the bootstrap (Efron and Tibshirani, 1993). The tables present the results of median of number series $(\mathrm{M})$, deviation intervals $(\mathrm{m})$ - for number series, correlation coefficients $(r)$, intervals of deviation the correlation coefficients $(\Delta r)$ and the results of statistical significance (p).

\section{Results}

The main results of the analysis of numerical rating of vascular-platelet hemostasis and the condition of endothelium are shown in Table 2 . The results of correlation analysis in groups of radiation-exposed and unexposed patients are shown in Tables 4 and 5.

The values of the ISA indicator in the control group were in the range of $21-58 \%$, with patients of the main group №2 - $47-76 \%$, with radiation-exposed patients' from main group №1 - 50 - 82\%. There were statistically significant differences on this indicator between both groups of patients and control the group (M2M1 = 1.31; M3M1 = 1.39). Significant differences between the groups of radiation-exposed and unexposed patients were not found. According to the average value of TIA corresponding differences with the control group were $\mathrm{M} 2 \mathrm{M} 1=1.24 ; \mathrm{M} 3 \mathrm{M} 1=1.28$ and also were statistically significant. The value of the ISD in the groups of examined patients with malignant neoplasms was reduced in correlation with control group. Thus, in the group of healthy individuals this indicator was in the range of 14 $31 \%$, patients with malignant neoplasms of the main group №2 - $10-18 \%$ and radiation-exposed patients had $8-14 \%$. The differences $(\mathrm{M} 1 \mathrm{M} 3=1.45 ; \mathrm{M} 1 \mathrm{M} 2=1.93$ and $\mathrm{M} 2 \mathrm{M} 3$ $=1.33$ ) between all groups were statistically significant.

The content of the WF was significantly exceeded in both groups of patients compared with the control (M3M1 $=1.31 ; \mathrm{M} 2 \mathrm{M} 1=1.71)$. The differences between the groups of patients were also significant $(\mathrm{M} 3 \mathrm{M} 2=1.30)$.

Therefore, in the analysis of some indices of vascular-platelet hemostasis was revealed the activation

Table 1. The Distribution of the Examined Patients with Malignant Neoplasms, Depending on the Nosology and the Relationship to Radiation Exposure

\begin{tabular}{lcc}
\hline \multicolumn{1}{c}{ Nosology } & $\begin{array}{l}\text { Main } \\
\text { group } \\
\text { No.1 }\end{array}$ & $\begin{array}{c}\text { Main } \\
\text { group } \\
\text { No.2, }\end{array}$ \\
\hline & $\mathrm{n}=83$ & $\mathrm{n}=70$ \\
$\begin{array}{l}\text { Stomach cancer II B - III A stage. } \\
\text { Cancer of the head of the pancreas III } \\
\text { stage }\end{array}$ & 31 & 28 \\
Rectal cancer II B - III A stage & 30 & 25 \\
\hline
\end{tabular}


Disorder of Endothelia Vessels' Functional State with Malignant Tumors in Patients Exposed Anthropogenic Radiation

Table 2. Indices of the Condition of Vascular-platelet Hemostasis with Malignant Neoplasms Examined Patients and in the Control Group

\begin{tabular}{|c|c|c|c|c|c|c|c|c|c|}
\hline \multirow[t]{2}{*}{ Indicator } & \multicolumn{2}{|c|}{$\begin{array}{c}\text { Control group } \\
\mathrm{n}=70\end{array}$} & \multicolumn{2}{|c|}{$\begin{array}{l}\text { Main group No.1, } \mathrm{n} \\
=83\end{array}$} & \multicolumn{2}{|c|}{$\begin{array}{c}\text { Main group No.2, } \\
\mathrm{n}=70\end{array}$} & \multirow[t]{2}{*}{ P1 - 2} & \multirow[t]{2}{*}{ P1 - 3} & \multirow[t]{2}{*}{$\mathrm{P} 2-3$} \\
\hline & M1 & $\mathrm{m}$ & M2 & $\mathrm{M}$ & M3 & $\mathrm{M}$ & & & \\
\hline ISA, $\%$ & 41.2 & 3.4 & 53.8 & 6.1 & 58.2 & 6.5 & 0.037 & 0.016 & 0.092 \\
\hline TIA, $\%$ & 60.5 & 5.1 & 74.8 & 6.6 & 77.7 & 6.2 & 0.042 & 0.023 & 0.151 \\
\hline ISD, $\%$ & 19.7 & 2 & 13.6 & 1.1 & 10.2 & 0.9 & 0.031 & 0.014 & 0.038 \\
\hline $\mathrm{WF}, \mathrm{mg} / \mathrm{ml}$ & 51.7 & 2.6 & 68.1 & 4.7 & 88.3 & 6 & 0.037 & 0.02 & 0.031 \\
\hline
\end{tabular}

*P1 - 2 - statistical significance of differences in the parameters of the control group with patients of the comparison group, P1 - 3 - control group with patients of the radiation-exposed group, P2 - 3 - between patients' groups

Table 3. Indices of Endothelial Function with Malignant Neoplasms Examined Patients and in the Control Group

\begin{tabular}{|l|c|c|c|c|c|c|c|c|c|}
\hline \multirow{2}{*}{ Indicator } & \multicolumn{2}{|c|}{ Control group, $\mathrm{n}=70$} & \multicolumn{2}{|c|}{ Main group No.1, $\mathrm{n}=83$} & \multicolumn{2}{c|}{ Main group No.2, $\mathrm{n}=70$} & \multirow{2}{*}{ P1 - 2} & P1 - 3 & P2 - 3 \\
\cline { 2 - 7 } & $\mathrm{M} 1$ & $\mathrm{M}$ & $\mathrm{M} 2$ & $\mathrm{~m}$ & $\mathrm{M} 3$ & $\mathrm{M}$ & & & \\
\hline $\begin{array}{l}\text { Content of } \\
\text { endothelial cells } \\
\text { in the peripheral } \\
\text { blood (for 1000 } \\
\text { platelets) }\end{array}$ & 2.2 & 0.1 & 4.9 & 0.3 & 7.5 & 0.4 & 0.017 & 0.004 & 0.022 \\
\hline $\begin{array}{l}\text { Content of met. } \\
\text { NO in blood, } \\
\text { mcg/ml }\end{array}$ & 41.3 & 2.4 & 57.4 & 3.5 & 53.3 & 7.8 & 0.021 & 0.029 & 0.215 \\
\hline $\begin{array}{l}\text { Indicator of } \\
\text { EDVD, } \%\end{array}$ & 18.6 & 1 & 12.7 & 1.2 & 9.5 & 0.6 & 0.013 & 0.003 & 0.019 \\
\hline
\end{tabular}

*P1 - 2 - statistical significance of differences in the parameters of the control group with the patients of the comparison group, P1 - 3 - control group with radiation-exposed patients group, $\mathrm{P} 2-3$ - between groups of patients

Table 4. The Indices of Correlation Between the Parameters of Endothelial Function and Vascular-platelet Hemostasis in Patients from Main Group No2

\begin{tabular}{|c|c|c|c|c|c|c|c|c|}
\hline \multirow{3}{*}{ Indices of endothelial function } & \multicolumn{8}{|c|}{ Indices of vascular-platelet hemostasis } \\
\hline & \multicolumn{2}{|c|}{ ISA } & \multicolumn{2}{|c|}{ TIA } & \multicolumn{2}{|c|}{ ISD } & \multicolumn{2}{|c|}{ WF } \\
\hline & $\mathrm{R}$ & $\Delta \mathrm{r}$ & $\mathrm{R}$ & $\Delta \mathrm{r}$ & $\mathrm{r}$ & $\Delta \mathrm{r}$ & $\mathrm{r}$ & $\Delta \mathrm{r}$ \\
\hline \multirow{2}{*}{$\begin{array}{l}\text { Content of endothelial cells in } \\
\text { peripheral blood }\end{array}$} & 0.452 & 0.021 & 0.392 & 0.03 & -0.299 & 0.017 & 0.555 & 0.022 \\
\hline & \multicolumn{2}{|c|}{$\mathrm{p}=0.038$} & \multicolumn{2}{|c|}{$\mathrm{p}=0.043$} & \multicolumn{2}{|c|}{$\mathrm{p}=0.040$} & \multicolumn{2}{|c|}{$\mathrm{p}=0.015$} \\
\hline \multirow{2}{*}{ Content of met. NO in blood } & 0.312 & 0.047 & 0.361 & 0.041 & -0.125 & 0.026 & 0.217 & 0.038 \\
\hline & \multicolumn{2}{|c|}{$\mathrm{p}=0.054$} & \multicolumn{2}{|c|}{$\mathrm{p}=0.048$} & \multicolumn{2}{|c|}{$\mathrm{p}=0.073$} & \multicolumn{2}{|c|}{$\mathrm{p}=0.062$} \\
\hline \multirow{2}{*}{ Indicator of EDVD } & -0.325 & 0.029 & -0.247 & 0.018 & 0.516 & 0.043 & -0.374 & 0.029 \\
\hline & \multicolumn{2}{|c|}{$\mathrm{p}=0.054$} & \multicolumn{2}{|c|}{$\mathrm{p}=0.048$} & \multicolumn{2}{|c|}{$\mathrm{p}=0.073$} & \multicolumn{2}{|c|}{$\mathrm{p}=0.062$} \\
\hline
\end{tabular}

of aggregation mechanisms in both groups of patients with malignant neoplasms, which is quite consistent with the concept of the combined genesis of thrombotic readiness for cancer. However, the question of the origin of this activation on the background of the disaggregation disorders remains. Is it a manifestation of the primary disorders of the structure and function of platelets? Or is it a consequence of their secondary pathological activation by the action of non-platelet factors? The reduction of the level and statistical significance of the differences between the groups of patients in terms of TIA against ISA is the evidence of a possible role of external influences on thrombocytes condition.

It is known that aggregation function of platelets is considerably connected with the condition of vascular endothelium (Forconi and Gori, 2013). Therefore, we suppose that one of the possible reasons for the increase of aggregation and the reduction of disaggregation ability of platelets with malignant neoplasms radiation-exposed patients can be structural and functional disorders of endothelium. As a check on this hypothesis, we conducted an appropriate laboratory and statistical analysis (Table $2,3)$.

The statistically significant differences in terms of the content of circulating endothelial cells in the peripheral blood among all groups of examined people were revealed. At the same time the excess of the indicator over the control group was the most expressed $(\mathrm{M} 3 \mathrm{M} 1=2.23$; $\mathrm{M} 2 \mathrm{M} 1=$ 3.40). However, the excess of this indicator in the group of radiation-exposed patients was also significant $(\mathrm{M} 2 \mathrm{M} 3=$ 1.53). Therefore, the presence of the endothelium damage in the radiation-exposed individuals before the cancer development can be revealed. Or the negative influence of neoplastic process on the condition of endothelial cells 
can be estimated. However, whatever the mechanisms are the result is the decreasing in resistance of endothelial cells with a combination of chronic radiation exposure and malignant neoplasm.

The content of NO metabolites in blood of the examined patients, as an indicator of the function of the vascular endothelium, was increased. This phenomenon, which reflects the pathological mechanisms of the overproduction of NO by the endothelium in the presence of local or systemic inflammation, hypoxia, activation of lipid peroxidation, is well known (Lacroix et al, 2012). However, in the group of radiation-exposed patients its average values were lower than in the main group No.2 (M3M2 = 1.08). Taking into account the important role of NO in regulation of aggregation and in the process of spontaneous disaggregation of thrombocytes, it must be assumed that this relative decreasing can play a definite role in revealed sharp decreasing of the disaggregation activity.

The parameter that most clearly defines the presence of endothelial dysfunction is the degree of EDVD. This parameter underwent the most significant decreasing in our research. Thus, according to the average values of this indicator the differences of M1M3 were 1.46, $\mathrm{M} 1 \mathrm{M} 2=1.96$ and M3M2 $=1.34$. Therefore, all received laboratory and instrumental data confirmed the presence of endothelial dysfunction with malignant neoplasms patients and its greater degree at the presence of chronic radiation-exposure anamnesis.

To specify the connection between the condition of the endothelium and vascular-platelet hemostasis we conducted a correlation analysis.

In both groups of examined patients statistically significant correlations between the content of endothelial cells in the blood were found, the level of EDVD and indices of hemostasis. The correlation coefficients of the last of these with the content of NO metabolites were significantly smaller.

A common feature at the evaluation of all results of the correlation analysis in chronically radiationexposed patients was significantly greater intensity of the correlations between indices of endothelial function and hemostasis system.

\section{Discussion}

Common for both groups of examined patients, who had or didn't have the effect of ionizing radiation in the anamnesis, was the presence of signs of endothelial dysfunction, characterized by the decreasing of endothelium-dependent vasodilatation (Puissant et al, 2014; Xu et al, 2014), the increasing levels of circulating endothelial cells in blood (Machalińska et al, 2011; Shilkina et al, 2014), as well as one of the most important endothelial factors of activation of the hemostasis - von Willebrand factor (Huck et al, 2014; Turner et al, 2014).

As a natural result was the excess of the degree of damage of the vascular endothelium in patients with malignant neoplasms, who had been previously exposed to radiation as a result of living in the areas of radiation risk of SNTS.
In spite of different expression of these features in different malignant neoplasms and in relation of various indices of endothelial function, the presence of general direction and data of dispersion and correlation analysis confirm the significant increase of the degree of endothelial dysfunction with radiation-exposed people.

The analysis of a number of indices of the system of hemostasis in the groups of patients with cancer indicates the presence of dependence between indices of endothelial function and the condition of hemostasis. These features are based on the presence of certain physiological interactions between the functional systems. The endothelium provides important mechanisms of hemostasis (Huck et al, 2014; Turner et al, 2014).

The degree of excess the indices of thrombotic readiness in patients with all listed in our research types of cancer who were exposed to ionizing radiation had a significant excess over the control group. This feature is characteristic of any form of cancer and is the basis of the risk of thrombotic complications constitute a large percentage of cancer deaths among the reasons (Elyamany et al, 2014; Franchini et al, 2015; Heit, 2015), as well as the progression of malignant tumors (Vlodavsky et al, 2007).

The results of the correlation analysis, which was carried out for the individual indices of the vascular endothelium condition and system of hemostasis, indicate the presence of close and highly significant correlations/ ties, which is additional evidence of the role of endothelial dysfunction in the formation of the disorders of hemostasis and the increase of the risk of thrombotic complications with previously radiation-exposed patients. This data is fully consistent with the existing model of relations between the vascular endothelium and the hemostatic system (McMichael, 2012; Chistiakov et al, 2015).

However, the determination of the influence of endothelial dysfunction on the course of neoplastic process can be associated with the revealed excess of degree of disorders of hemostasis system.

In conclusion, It is known that thrombotic complications are the second most common direct cause of deaths of oncologic patients (Elyamany et al, 2014; Franchini et al, 2015). Taking into account the use of modern methods of treatment the patients with distant metastases, this factor comes to the fore (Epstein and O'Reilly, 2012; Trujillo Santos, 2012). The risk of cancer spread (metastasing) in the presence of evident endothelial increases due to three mechanisms - the increase of the permeability of the endothelium for the cellular elements of the tumor (Rebelo et al, 2009), the increase of thromboembolic potential and the negative impact of endothelial dysfunction on the state of the immune system as a result of cytokine imbalance (Pober et al, 2009).

Besides, it should be mentioned that according to the data of most researches the endothelial dysfunction also conduces the neovascularization of metastatic masses (Arnes et al, 2012; Ramcharan et al, 2015).

\section{References}

Aird WC (2015).Endothelium and haemostasis. Hamostaseologie. 35, 11-6. 
Arnes JB, Stefansson IM, Straume O, et al (2012). Vascular proliferation is a prognostic factor in breast cancer. Breast Cancer Res Treat, 133, 501-10.

Bauer S, Gusev BI, Pivina LM, et al (2005). Radiation exposure due to local fallout from Soviet atmospheric nuclear weapons testing in Kazakhstan: solid cancer mortality in the Semipalatinsk historical cohort, 1960-1999. Radiat Res. 164, 409-19.

Celermajer DS (1998). Testing endothelial function using ultrasound. J Cardiovasc Pharmacol, 32, 29-32.

Chistiakov DA, Revin VV, Sobenin IA, et al (2015). Vascular endothelium: functioning in norm, changes in atherosclerosis and current dietary approaches to improve endothelial function. Mini Rev Med Chem, 15, 338-50.

Daly C, Urbach DR, Stukel TA, et al (2015). Patterns of diagnostic imaging and associated radiation exposure among long-term survivors of young adult cancer: a populationbased cohort study // BMC Cancer, 15, 612 .

Eelen G, de Zeeuw P, Simons M, et al (2015). Endothelial cell metabolism in normal and diseased vasculature. Circ Res, 116, 1231-44.

Efron B, Tibshirani RJ (1993). An introduction to the bootstrap. New York: Chapman \& Hall.

Elyamany G, Alzahrani AM, Bukhary E (2014). Cancerassociated thrombosis: an overview. Clin Med Insights Oncol, 8, 129-37.

Epstein AS, O'Reilly EM (2012). Exocrine pancreas cancer and thromboembolic events: a systematic literature review.J Natl Compr Canc Netw, 10, 835-46.

Forconi S, Gori T (2013). Endothelium and hemorheology. Clin Hemorheol Microcirc, 53, 3-10.

Franchini M, Bonfanti C, Lippi G (2015). Cancer-associated thrombosis: investigating the role of new oral anticoagulants. Thromb Res, 135, 777-81.

Heit JA (2015). Epidemiology of venous thromboembolism. Nat Rev Cardiol, 12, 464-74.

Hladovec J (1978). Circulating endothelial cells as a sign of vessel wall lesions. Physiol Bohemoslov, 27, 140-4.

Huck V, Schneider MF, Gorzelanny C, et al (2014). The various states of von Willebrand factor and their function in physiology and pathophysiology. Thromb Haemost, 111, 598-609.

Lacroix S, Rosiers CD, Tardif JC, et al (2012). The role of oxidative stress in postprandial endothelial dysfunction. Nutr Res Rev, 25, 288-301.

Laurier D, Gay D (2015). Risks associated to ionizing radiation from natural sources. Rev Prat, 65, 74-8.

Machalinska A, Safranow K, Sylwestrzak Z, et al (2011). Elevated level of circulating endothelial cells as an exponent of chronic vascular dysfunction in the course of AMD. Klin Oczna, 113, 228-32.

McMichael M (2012). New models of hemostasis. Top Companion Anim Med, 27, 40-5.

Molina JA, Jiménez-Jiménez FJ, Navarro JA, et al (1995). Serum levels of nitrates in focal cerebral ischemia. Eur $J$ Neurol, 2, 225-7.

Moysich KB, Menezes RJ, Michalek AM, et al (2002). Chernobyl-related ionising radiation exposure and cancer risk: an epidemiological review. Lancet Oncol, 3, 269-79.

Okutan O, Ayten O (2014). Venous thromboembolism and cancer. Tuberk Toraks, 62, 301-15.

Pober JS, Min W, Bradley JR (2009). Mechanisms of endothelial dysfunction, injury, and death. Annu Rev Pathol, 4, 71-95.

Puissant C, Abraham P, Durand S, et al (2014). Endothelial function: role, assessment and limits. J Mal Vasc, 39, 47-56.

Ramcharan KS, Lip GY, Stonelake PS, et al (2015). Increased pre-surgical numbers of endothelial progenitor cells and circulating endothelial cells in colorectal cancer fail to predict outcome. Int J Colorectal Dis, 30, 315-21.

Rebelo SL, Amel-Kashipaz MR, Radford PM, et al (2009). Novel markers of inflammation identified in tumor necrosis factor receptor-associated periodic syndrome (TRAPS) by transcriptomic analysis of effects of TRAPS-associated tumor necrosis factor receptor type I mutations in an endothelial cell line. Arthritis Rheum, 60, 269-80.

Shah DJ, Sachs RK, Wilson DJ (2012). Radiation-induced cancer: a modern view // British J Radiol, 85, 1166-73.

Shilkina NP, Butusova SV, Driazhenkova IV (2014). System of microcirculation, markers of vascular wall damage and systematicity of the process in rheumatic diseases. Angiol Sosud Khir, 20, 27-34.

Shore RE (2009). Low-dose radiation epidemiology studies: status and issues. Health Phys, 97, 481-6.

Strzelczyk JJ, Damilakis J, Marx MV, et al (2007). Facts and controversies about radiation exposure, part 2: low-level exposures and cancer risk. J Am Coll Radiol, 4, 32-9.

Trujillo Santos AJ (2012). Management of thromboembolic risk in patients with cancer. Med Clin (Barc). 139, 31-5.

Turner N, Nolasco L, Nolasco J, et al (2014). Thrombotic microangiopathies and the linkage between von Willebrand factor and the alternative complement pathway. Semin Thromb Hemost, 40, 544-50.

Verhamme P, Hoylaerts MF (2006). The pivotal role of the endothelium in haemostasis and thrombosis. Acta Clin Belg, 61, 213-9.

Vlodavsky I, Ilan N, Nadir Y, et al (2007). Heparanase, heparin and the coagulation system in cancer progression. Thromb Res, 120, 112-20.

$\mathrm{Xu}$ Y, Arora RC, Hiebert BM, et al (2014). Non-invasive endothelial function testing and the risk of adverse outcomes: a systematic review and meta-analysis. Eur Heart $J$ Cardiovasc Imaging, 15, 736-46. 